\title{
Vinyl Chloride or Derivatives Exposure
}

National Cancer Institute

\section{Source}

National Cancer Institute. Vinyl Chloride or Derivatives Exposure. NCI Thesaurus. Code C157509.

Environmental, occupational, or consumer-based exposure to vinyl chloride or its derivatives during the manufacture or breakdown of polyvinyl chloride (PVC) and other vinyl containing products. 